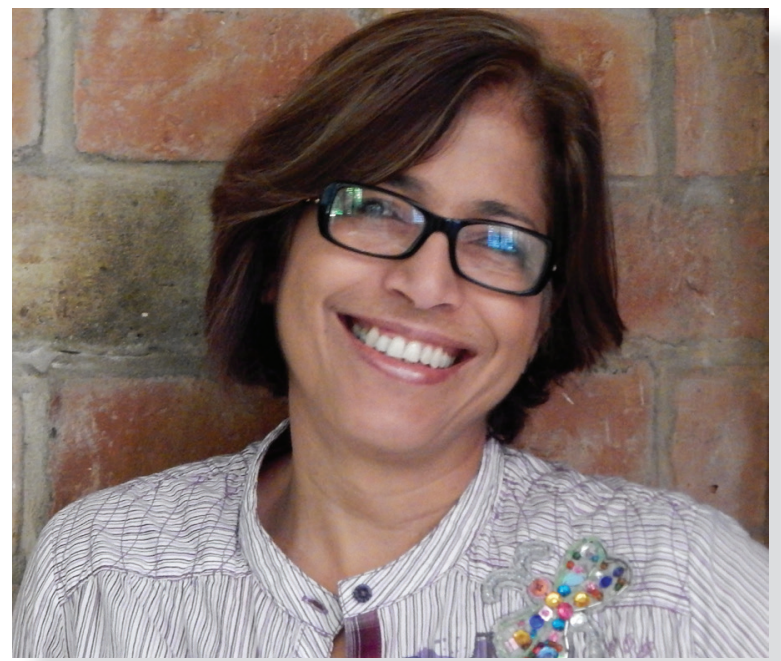

\title{
Factores que determinan el sentido de pertenencia de los estudiantes de la PUCMM-CSTA
}

\author{
Factors that determine PUCMM-CSTA \\ students' sense of belonging
}

Leyda Brea Sención*

Recibido: 02-12-15

Aprobado: 08-03-16

\section{Resumen}

El sentido de pertenencia es un sentimiento de identificación de las personas a un grupo o a un lugar que incluye componentes afectivos y de compromiso que se derivan de esta identificación. Integra una dimensión psicológica, una afectiva y una física. En los contextos educativos, emerge una dimensión académica. Este sentimiento está configurado por factores relativos a las dimensiones mencionadas y la forma en que estos se manifiestan puede obstaculizarlo o facilitarlo. Esta investigación persigue conocer los factores que determinan el sentido de pertenencia de los estudiantes de la Pontificia Universidad Católica Madre y Maestra (PUCMM-CSTA), y analizar la influencia de estos factores en el desempeño académico, en la identificación con la escuela de la carrera y con la Universidad. Para lograrlo, se llevó a cabo un estudio que permitió medir el grado en que se manifiestan estos factores y su relevancia, a partir de las informaciones obtenidas mediante un cuestionario aplicado a una muestra de 238 estudiantes de las distintas carreras de grado que se ofrecen en la institución. Atendiendo a los resultados, se concluyó que la pertinencia curricular, el apoyo de los profesores y del departamento, una planta física funcional y un clima permeado por el afecto y la cordialidad contribuyen a que se sientan pertenecer a la Universidad y a facilitar el buen desempeño académico.

\section{Abstract}

Belonging is a sense of personal identification with a group or place that generally results in the development of affective bonds and feelings of obligation. It involves psychological, affective and physical dimensions. In educational contexts, an academic dimension emerges. This research aims to understand the factors that determine Pontificia Universidad Catolica Madre y Maestra (PUCMM-CSTA) students' sense of belonging. Moreover, it analyzes whether those factors have an effect on academic performance and students' sense of belonging with respect to University faculty that hosts their program of study. The research uses data collected through a sample of 238 undergraduate students distributed throughout all fields of study. Results show that curricular relevance, teacher and departmental support, user-friendly university infrastructure and a school climate characterized by personnel warmth increase students' sense of belonging and encourage their academic performance.

\section{Palabras clave}

sentido de pertenencia; implicación académica; clima de aula; estudiantes universitarios.

\section{Keywords}

Sense of belonging, academic implications, classroom climate, college students

\footnotetext{
*Leyda Brea Sención: Doctora en Educación por la Universidad de Murcia. Magíster en Gestión de proyectos en la Universidad de Quebec. Realizó estudios de Arquitectura en la Universidad Nacional Pedro Henríquez Ureña. Ha compartido su ejercicio profesional de dirección de proyectos de diseño arquitectónico y urbano con la docencia. Es profesora a tiempo completo del Departamento de Arquitectura PUCMM. Para contactar a la autora: leydabrea@pucmm.edu.do; leydabrea@gmail.com.
} 


\section{Introducción}

El sentido de pertenencia se ha definido como un sentimiento de arraigo y vinculación de un individuo con un grupo o con un ambiente determinado. A partir de él emergen lazos afectivos que generan en la persona actitudes positivas hacia el grupo y el lugar. Entre estas se incluyen el deseo de participar en su desarrollo y la construcción de significados que luego formarán parte de la memoria personal y del grupo.

Numerosas investigaciones en el ámbito educativo han dado cuenta de la relación existente entre el sentido de pertenencia al centro educativo y una experiencia académica positiva. Estos hallazgos motivaron la realización en el año 2008 de un estudio diagnóstico con el objetivo de verificar la existencia de este sentimiento en los estudiantes de Arquitectura de la PUCMM-CSTA (Brea, 2009).

Más tarde, se amplió esta investigación para indagar sobre los factores que determinan este sentimiento en dichos estudiantes (Brea, 2015) y más adelante, en una muestra representativa de todas las carreras de la universidad. El artículo que se presenta a continuación resume los hallazgos de este último estudio cuyos resultados no arrojaron diferencias significativas por carrera, lo que ha permitido validar y generalizar el conocimiento adquirido. Con base en esto, cuando se haga referencia a los informantes no se especificará la carrera a la que pertenecen.

Una revisión de investigaciones y de una literatura multidisciplinar que incluyó contenidos de Educación, Sociología, Arquitectura, Geografía urbana, Psicología social permitió definir el sentido de pertenencia como un sentimiento de identificación de las personas con un grupo o con un lugar que incluye componentes afectivos y de compromiso que subyacen a esta identificación (Fenster, 2005; Lehmann, 1994; Maslow, 1954; Osterman, 2000; Vidal \& Pol, 2005; Willms, 2003). El sentido de pertenencia se construye sobre la base de las experiencias individuales y colectivas que resultan de la interacción de los individuos con los demás y con los diferentes lugares donde se desenvuelve.

"Este sentimiento se relaciona con conceptos como identidad social e identidad de lugar los cuales describen los modos de las personas relacionarse y las diferentes escalas y niveles de interacción de las personas con los lugares que habitan, laboran y estudian.

En el ámbito educativo, el sentido de pertenencia se ha vinculado a los conceptos conexión, compromiso e implicación, los cuales aluden a los sentimientos, al involucramiento y las interacciones del estudiantado con los diferentes actores y ambientes del centro educativo. También se ha relacionado con el logro académico (González, 2010; Leff, 1978; Soria, Martínez, Esteve, Gumbau, \& Gumbau, 2005; Thompson, 2007; Vargas, 2007).

Entre las repercusiones de un sentido de pertenencia fortalecido al centro educativo se encuentran: la potenciación de comportamientos orientados al disfrute de la experiencia académica y al buen desempeño, el bienestar psicológico, el desarrollo social y una

Figura I

Repercusiones de un sentido de pertenencia fortalecido

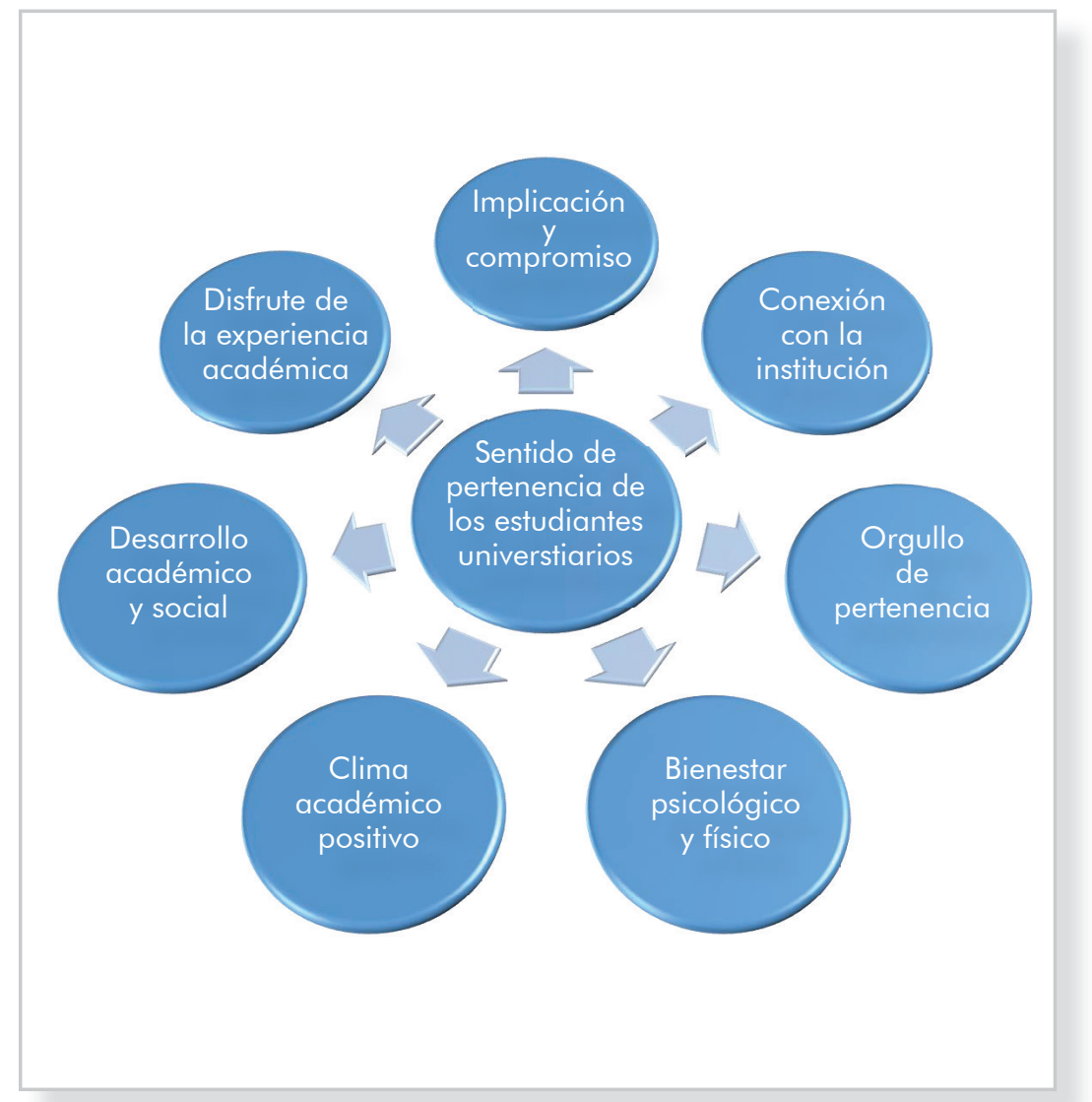

Fuente: elaborada por el autor 
identificación con la institución que modela el perfil de estudiantes y egresados.

Dimensiones y factores del sentido de pertenencia de los estudiantes universitarios

El sentido de pertenencia se describe en la investigación y en la literatura a partir de sus dimensiones: la psicológica-social, que describe los procesos relacionados con la afiliación, como estabilidad emocional y el sentirse integrado socialmente; la afectiva, relacionada con los sentimientos, la percepción de apoyo y las interacciones resultantes de esa afiliación; la dimensión física, que se refiere a las características de los escenarios donde se verifican estas experiencias, como la funcionalidad y el confort.

Con la mirada puesta en la universidad, Strayhorn (2012) y González (2010) realizan un amplio análisis acerca de la dimensión académica del sentido de pertenencia, que apunta a los aspectos específicos de la vida de los estudiantes, tales como la pertinencia del currículo y el clima del aula. Es importante resaltar que los elementos de estas dimensiones se entrelazan, por lo que sus fronteras son difusas.

El sentido de pertenencia se perfila como una variable susceptible a las características del ambiente, por lo que numerosas investigaciones se han realizado con el propósito de caracterizar un ambiente que favorezca la construcción del sentido de pertenencia. Así, para los centros educativos se describe un ambiente afectivo y social que promueve la identificación y la interacción (Hargreaves, 1986; Pérez, 2010; Stokols, 1977); un ambiente físico representado por espacios que respondan a los procesos didácticos y por un campus que refleje la misión del centro (Corraliza, 1987; Kenney, Dumont, \& Kenney, 2005; Proshansky, Fabian, \& Kaminoff, 1983); un ambiente académico que propicie la autorrealización (Boyer, 1990; Freeman, Anderman, \& Jensen, 2007; Thomas, 2012).

En síntesis, el sentido de pertenencia florece en ambientes posibilitadores de comportamientos $y$ actitudes positivas hacia el aprendizaje, hacia el grupo y hacia la institución educativa.

De esta manera, tras una minuciosa revisión de la literatura y de investigaciones se elaboró un mapa con más de 90 factores y sub-factores determinantes del sentido de pertenencia (figura 2) que se corresponden con las dimensiones y ambientes descritos los cuales se clasifican en:

- Afectivos: aluden al involucramiento de sentimientos y emociones de los estudiantes hacia el grupo con el que interactúa (profesores, compañeros, personal académico y administrativo) y hacia el lugar donde desarrolla su vida académica.

- Sociales: hacen referencia al sentimiento de formar parte de la colectividad y a las características de la interacción social con profesores y compañeros.

- Académicos: apuntan a la experiencia formativa en cuanto a los contenidos, su transmisión y las características organizativas del ambiente en que se insertan.

- Físicos: dan cuenta de la interacción entre las personas y los lugares, de la manera en que estos llenan los cometidos, forman parte inherente de la experiencia formativa y se convierten en escenarios con significado.

El conocimiento de estos factores y el de sus consecuencias es clave para la formulación de acciones conducentes a la conformación de los ambientes descritos y al fortalecimiento de este sentimiento.

\section{Objetivos del estudio}

Para la realización del estudio se plantearon las siguientes preguntas: ¿cuáles son los factores que determinan el sentido de pertenencia de los estudiantes? ¿Se relaciona este sentimiento con el desempeño académico?

Para responder estas preguntas, se desarrolla una investigación cuyo objetivo general es conocer los factores que determinan el sentido de pertenencia de los estudiantes universitarios y su relación con el desempeño académico.

Como objetivos específicos se proponen: comprender las dimensiones del sentido de pertenencia; conocer los factores determinantes de este sentimiento, la frecuencia en que se manifiestan, así como la influencia en la identificación con la escuela de la carrera y con la Universidad.

Se pretende también precisar la relevancia de cada factor. 


\section{Figura 2}

Factores determinantes del sentido de pertenencia de los estudiantes universitarios

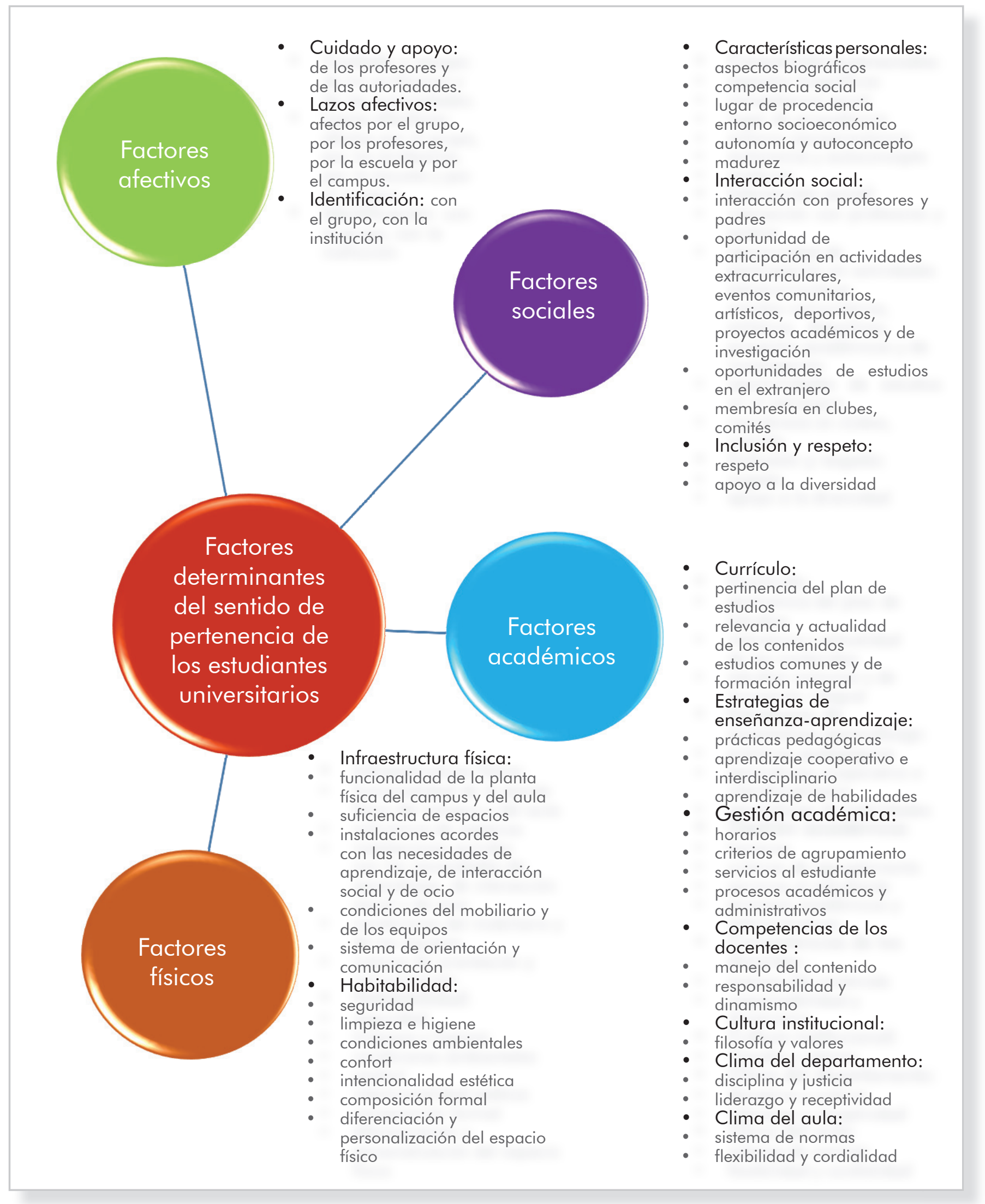

Fuente: elaborada por el autor 


\section{Aspectos metodológicos}

\section{Contexto de la investigación, diseño y muestra}

El contexto de esta investigación es el Campus Santo Tomás de Aquino de la Pontificia Universidad Católica Madre y Maestra. Se corresponde con los estudios de diseño descriptivo no experimental. Se recogieron los datos de la propia voz de los sujetos, por tanto, sus puntos de vista y sus reflexiones se consideraron como datos concretos analizables.

Este procedimiento se enmarca dentro de la estrategia de escuchar la voz del alumnado (Salvador, 2010), una práctica que permite al investigador aproximarse a la realidad en que vive $y$, de ese modo, comprender sus niveles y formas de identificación con los diferentes ámbitos de la vida académica.

La población del estudio son los 4,750 alumnos activos en el segundo periodo del año académico 2014-2015. Se tomó una muestra de 238 estudiantes equivalente al $5 \%$ de la población, constituida por estratos de las 16 carreras que se cursan en la universidad. Para la selección de los informantes se establecieron dos criterios: más de dos años de estudios y un buen desempeño académico (índice entre 2.7 y 4.0) de modo que contasen con cierta experiencia universitaria, pudiesen reconocer factores determinantes del sentido de pertenencia y relacionar estos con su desempeño.

\section{Variables y procedimiento}

Como factor se ha definido un elemento o situación que condiciona un resultado. Las variables en esta investigación son los factores que determinan el sentido de pertenencia, descritos e identificados en la revisión de la literatura y la investigación. Los indicadores son las evidencias de la manifestación de estos factores, que se revelan en forma de repercusiones. Se elaboró un instrumento donde se resumieron estos factores, para recoger la percepción de un buen número de estudiantes de la PUCMM-CSTA, a fin de conocer aquellos que hacen posible que el sentido de pertenencia se desarrolle en ellos. Este instrumento consistió en un cuestionario de preguntas cerradas, en forma de matriz, de cinco columnas y veinte filas que vinculó los factores que determinan el sentido de pertenencia con cuatro aspectos a medir etiquetados en forma de preguntas de la siguiente manera: Con la letra $A$, el grado en que se experimentan los factores; con la $B$, la influencia de estos en el desempeño académico; en la identificación con la escuela de la carrera con la $C$, y con la Universidad con la $D$.
Los veinte factores y las cuatro preguntas dieron como resultado un instrumento de 80 ítems (Anexo1): 32 en el aspecto $A ; 16$ en el $B ; 16$ en el C; 16 en el D. Los participantes debían responder a las preguntas según una escala tipo Likert con cuatro opciones de respuestas: muy poco, algo, bastante o mucho. Se eliminó la opción neutral para perseguir precisión.

La información obtenida se transfirió al paquete estadístico SPSS para su análisis. Se obtuvo la distribución de frecuencias la cual permitió conocer los factores más o menos favorecidos y la media aritmética de cada uno de los aspectos medidos (A, B, C, D). Esta medición informó sobre la relevancia del factor para la construcción de sentido de pertenencia, pues cuanto mayor el valor de la media, más relevante el factor.

\section{Resultados}

El $70 \%$ de los informantes son dominicanos, mujeres, cursaron el bachillerato en la capital y proceden de colegios privados. Poco más de la mitad se costea sus estudios con fondos propios, el resto con crédito educativo o algún tipo de beca. No se evidenciaron diferencias de importancia derivadas de esta composición en las medidas en que los factores analizados se manifiestan e influyen en el desempeño y en la identificación.

Las frecuencias relativas de las respuestas recogidas en el cuestionario indican el mayor o menor grado en que los estudiantes experimentan los factores indicados, perciben que influyen en su desempeño académico y que contribuyen a la identificación con la escuela de la carrera y con la universidad. A continuación los resultados derivados de las respuestas de los estudiantes consultados seguidos de algunos comentarios.

\section{Grado en que se experimentan los factores}

\section{Factores afectivos}

Los resultados revelan que más de la mitad de los estudiantes experimenta poco la disponibilidad de los profesores $(60 \%)$ y el seguimiento personalizado $(76 \%)$. Revelan además que la mayoría siente afecto por su grupo de compañeros (82\%) y por algunos de sus profesores (74\%). Asimismo, el $85 \%$ atribuye mucha importancia a la escuela de su carrera y el $67 \%$ comparte la filosofía y los valores de la institución entre bastante y mucho. En esa misma medida, casi todos $(81 \%)$ se sienten integrados al grupo y orgullosos de pertenecer a la Universidad. 
Los resultados revelan que en la medida en que los alumnos se sienten conectados con profesores y compañeros y consideran importante su escuela, se fortalece el vínculo afectivo con las personas y con los escenarios de la vida académica. Probablemente, una de las causas que inciden en la percepción de poca disponibilidad de los profesores es que, en la PUCMM, la mayoría de ellos son contratados por asignatura; es decir, que su compromiso está limitado a las horas de clase.

\section{Gráfico 1}

Histograma Grado en que se experimentan los factores afectivos

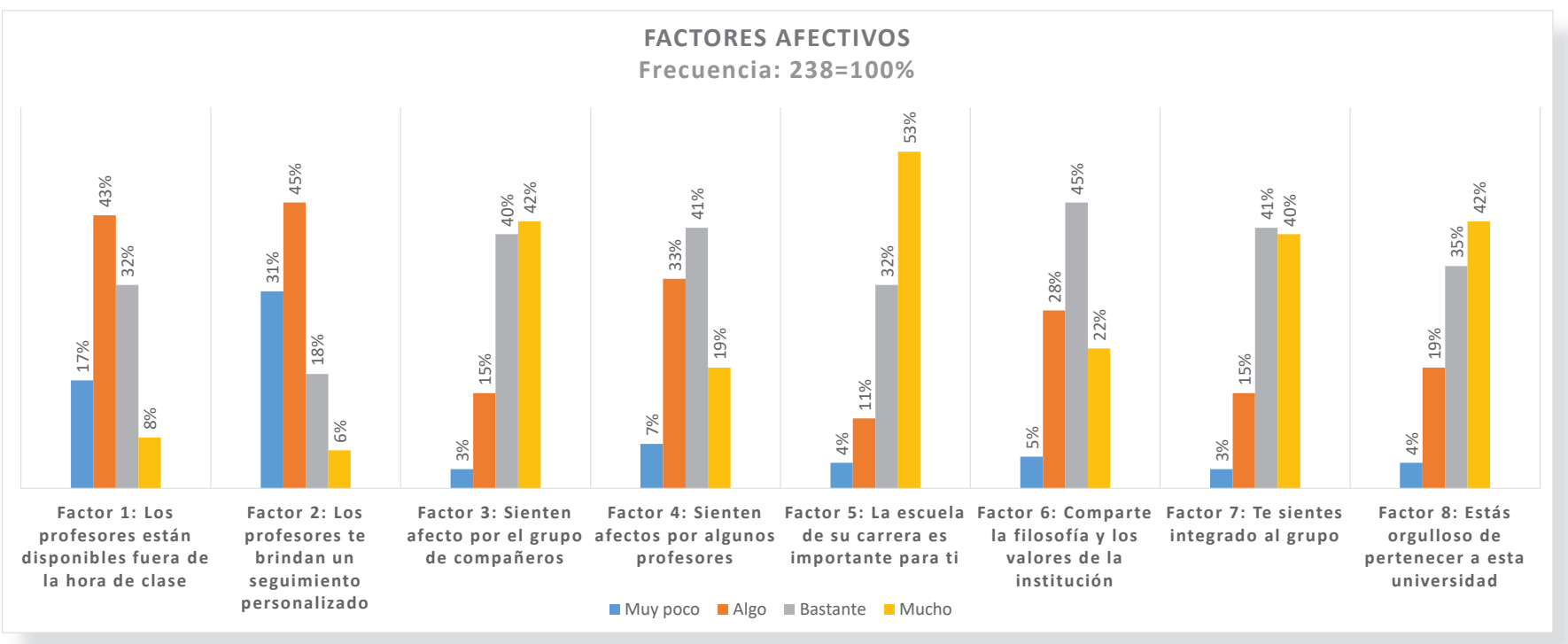

\section{Factores sociales}

Las respuestas indican que la mayoría de los estudiantes $(70 \%)$ hace amigos con facilidad y se sienten seguros de sí mismos en la Universidad entre bastante y mucho. Similar porcentaje revela que experimenta que en la Universidad se promueve el trabajo en equipo y el espíritu de grupo, sin embargo, la promoción de la interacción social es poco experimentada por la mayoría de los estudiantes.

\section{Gráfico 2}

Histograma Grado en que se experimentan los factores sociales

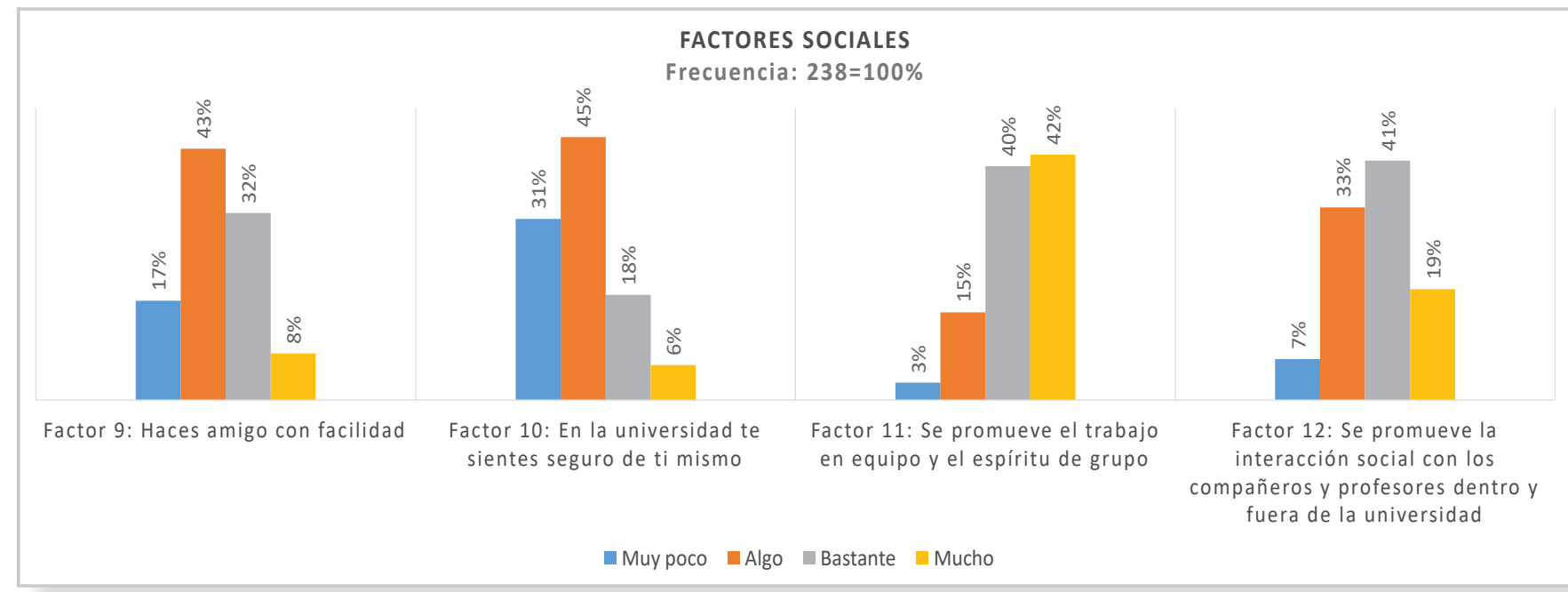

Estas respuestas confirman la importancia que tiene la habilidad para hacer amigos en la interacción positiva entre los estudiantes. Conjuntamente con el factor sentirse seguro de sí mismo, se enfatiza la importancia de la dimensión psicológica del sentido de pertenencia y junto a la promoción del trabajo en equipo propicia la generación de lazos afectivos entre ellos. 


\section{Factores académicos}

Poco más de la mitad de los estudiantes (54\%) expresa que experimenta entre poco y algo que las actividades en el aula son dinámicas y variadas; la mayoría (82\%) experimenta entre bastante y mucho que los contenidos son actuales y aplicables en el mundo real y que el departamento de su carrera realiza una planificación pensando en ellos. En esa misma medida, experimentan un clima de disciplina y cordialidad en el aula.

\section{Gráfico 3}

Histograma Grado en que se experimentan los factores académicos

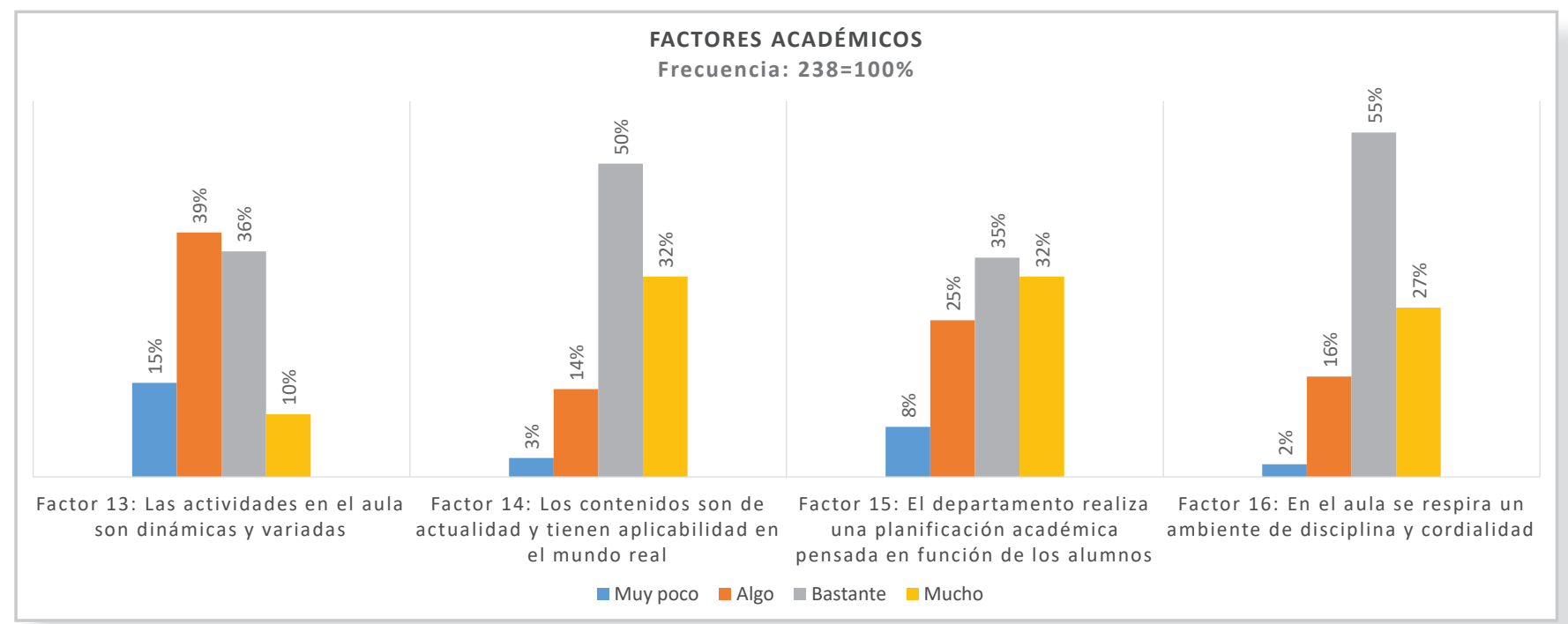

Se expresa en estos resultados la importancia de lo que acontece en el aula en cuanto a clima, estrategias didácticas y pertinencia de los contenidos para el fortalecimiento de sus vínculos afectivos. En ese mismo orden, se destaca la importancia de la planificación que realiza el departamento en la vida universitaria, ya que los alumnos se sienten más apoyados y apegados en la medida que perciben que el departamento está para ayudarles a ser más eficaces en su vida académica.

\section{Factores físicos}

Más del $74 \%$ de los estudiantes expresa que experimenta entre bastante y mucho la funcionalidad de la planta física y se siente seguro y a gusto en la Universidad, mientras que poco más de la mitad dice que cuenta con lugares para el ocio o con lugares favoritos en el campus.

\section{Gráfico 4}

Histograma Grado en que se experimentan los factores físicos

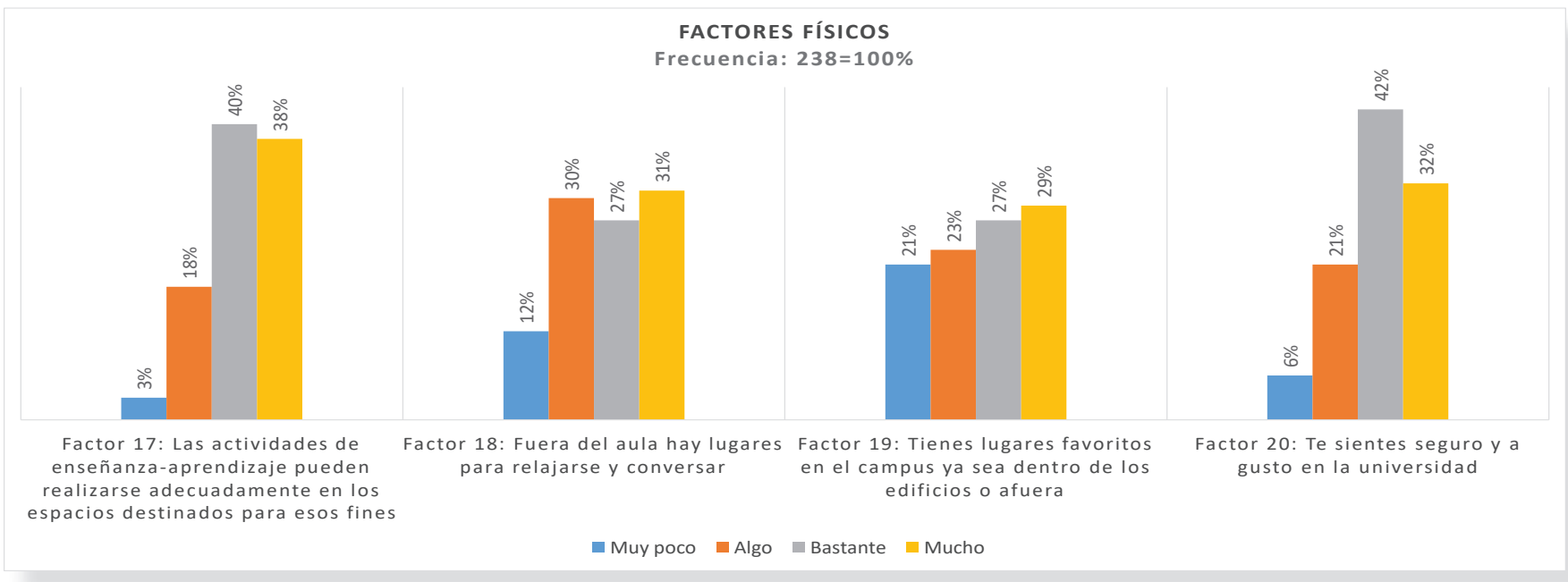

"Factores que determinan el sentido de pertenencia de los estudiantes de la PUCMM-CSTA", Leyda Brea Sención. 
Los alumnos experimentan la importancia de contar con espacios donde construir los significados que formarán parte de su historia y su memoria. Estos resultados informan sobre la valoración positiva de los estudiantes hacia el ambiente físico.

\section{Grado en que los factores influyen en el desempeño académico}

\section{Factores afectivos}

Más de la mitad de los estudiantes considera que influye entre bastante y mucho en su desempeño académico la disponibilidad de los profesores fuera de las horas de clase (60\%) y compartir la filosofía y los valores de la institución (57\%). Por otra parte, en similar medida más del $70 \%$ considera que el seguimiento personalizado, sentir afecto por el grupo de compañeros y por los profesores, considerar importante la escuela de la carrera y sentirse integrado al grupo también influye en su desempeño académico y un $66 \%$ considera que también influye en esto el orgullo que sienten de pertenecer a la universidad.

\section{Gráfico 5}

Histograma Influencia en el desempeño de los factores afectivos

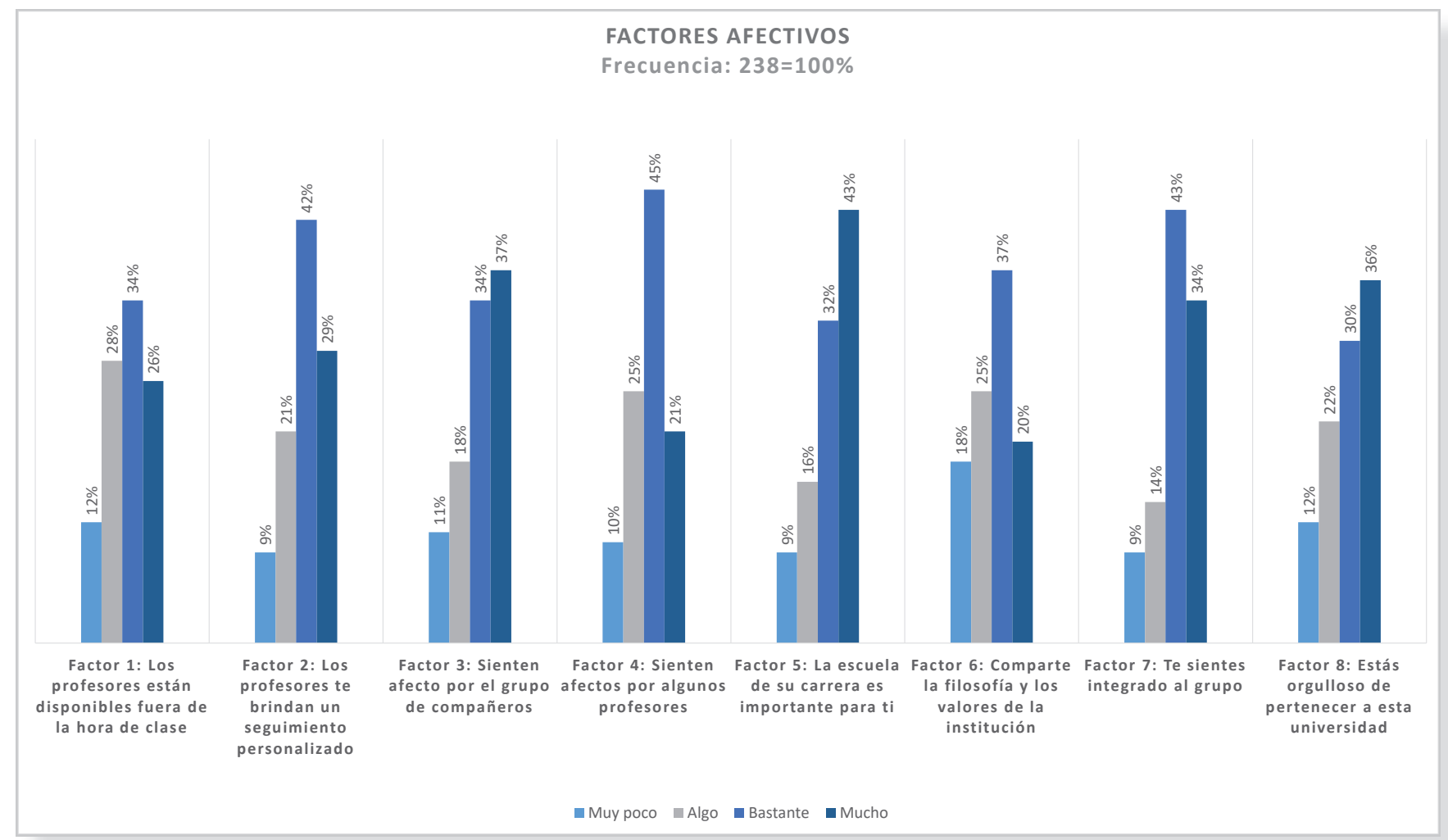

Las respuestas de los estudiantes revelan que es importante contar con profesores que puedan dedicar más tiempo al estudiantado fuera del aula. Numerosos estudios han demostrado que cuando los alumnos perciben que son objeto de un seguimiento personalizado, tienden a reciprocar el esfuerzo de sus profesores. Del mismo modo, la importancia atribuida a la escuela de la carrera se relaciona con los beneficios que obtendrán de sus estudios, lo que suele producir un aumento en la participación en las clases y actividades que también influye en su desempeño académico.

\section{Factores sociales}

Las respuestas indican que el $60 \%$ de los estudiantes considera que hacer amigos con facilidad influye en su buen desempeño académico y la mayoría (más del 70\%) considera que también contribuye sentirse seguro de sí mismos, la promoción del trabajo en equipo y el espíritu de grupo. Por otra parte, poco más de la mitad de los estudiantes (53\%) percibe que la promoción de la interacción social influye poco en su buen desempeño académico. 


\section{Gráfico 6}

Histograma Influencia en el desempeño de los factores sociales

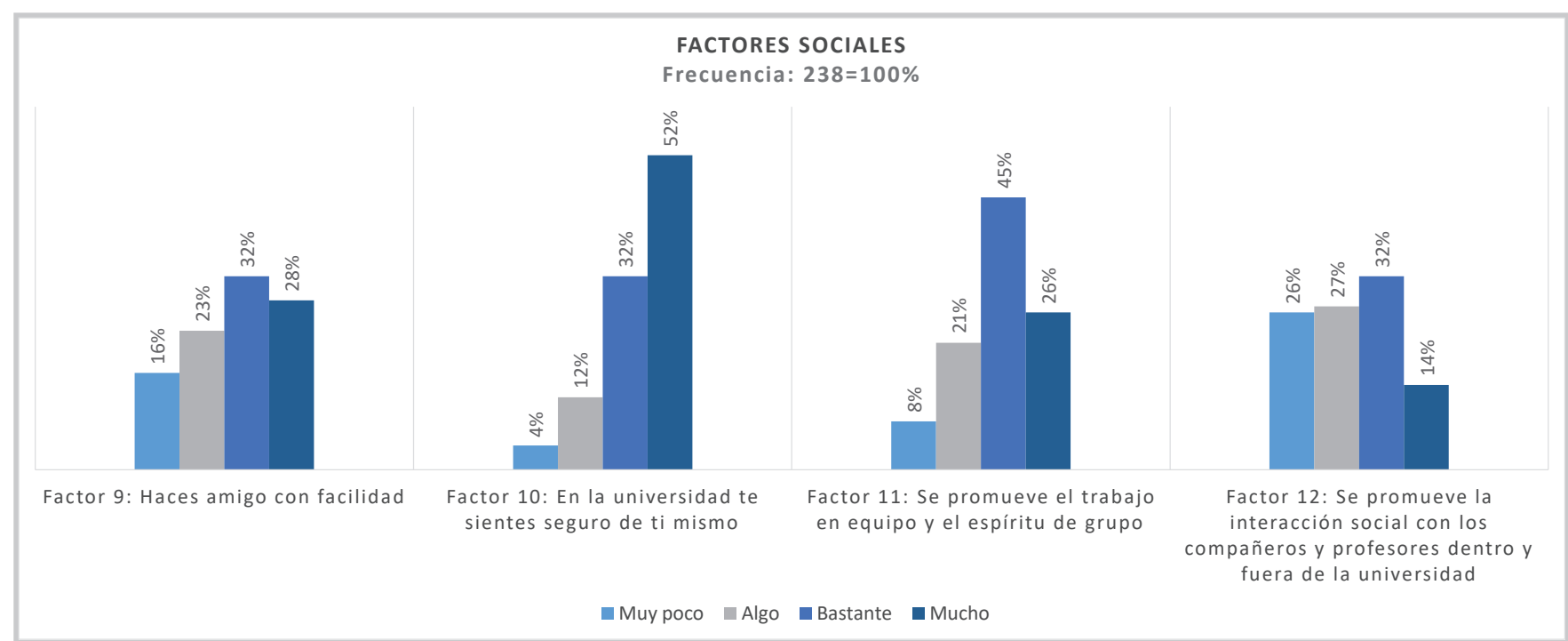

Los factores habilidad para hacer amigos y sentirse seguro de sí mismo hacen referencia a la dimensión psicológica y social del sentido de pertenencia que se sitúa entre los aspectos que fundamentan una experiencia académica de calidad. Esta dimensión se fortalece con la promoción del trabajo en equipo por ser una práctica pedagógica que fortalece la integración social y grupal, la permanencia y el logro académico.

\section{Factores académicos}

La gran mayoría de los estudiantes considera que el dinamismo y la variedad de las actividades en el aula (75\%), la pertinencia de los contenidos (90\%), la planificación académica que realiza el departamento (82\%) y un buen clima de aula (89\%), influyen entre bastante y mucho en su buen desempeño académico.

En estos resultados se revela la importancia del ambiente áulico para el logro académico de los estudiantes. Se reconoce la influencia de las estrategias didácticas y los contenidos relevantes en la motivación y la implicación. Los alumnos perciben que un aula con un buen clima, donde se promueve un ambiente de cordialidad y respeto contribuye a mejorar la disposición para el aprendizaje. Asimismo, al ser el mecanismo organizativo de las asignaturas (en cuanto a bloques, temas, tanda, plan de estudios, agrupamiento), la planificación se revela como un instrumento facilitador del desarrollo académico y la eficacia académica del alumnado.

\section{Gráfico 7}

Histograma Influencia en el desempeño de los factores académicos

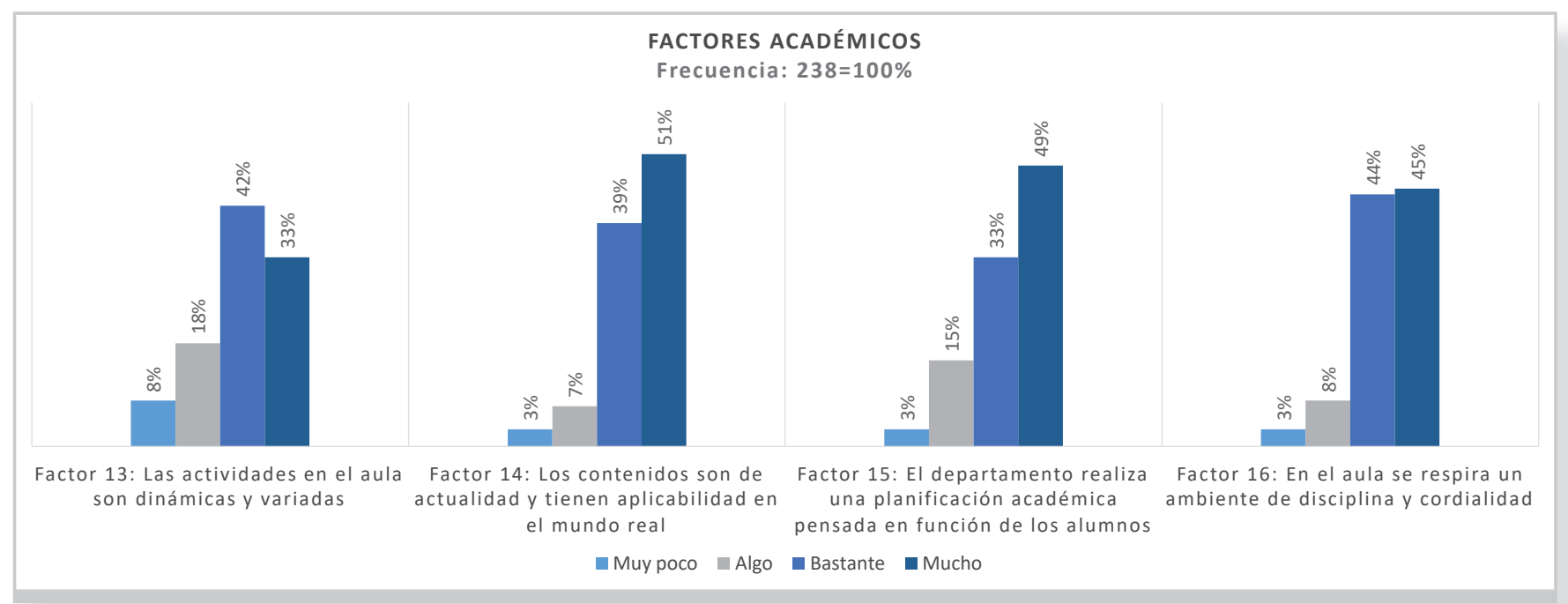

"Factores que determinan el sentido de pertenencia de los estudiantes de la PUCMM-CSTA», Leyda Brea Sención. 


\section{Factores físicos}

\section{Gráfico 8}

Histograma Influencia en el desempeño de los factores físicos

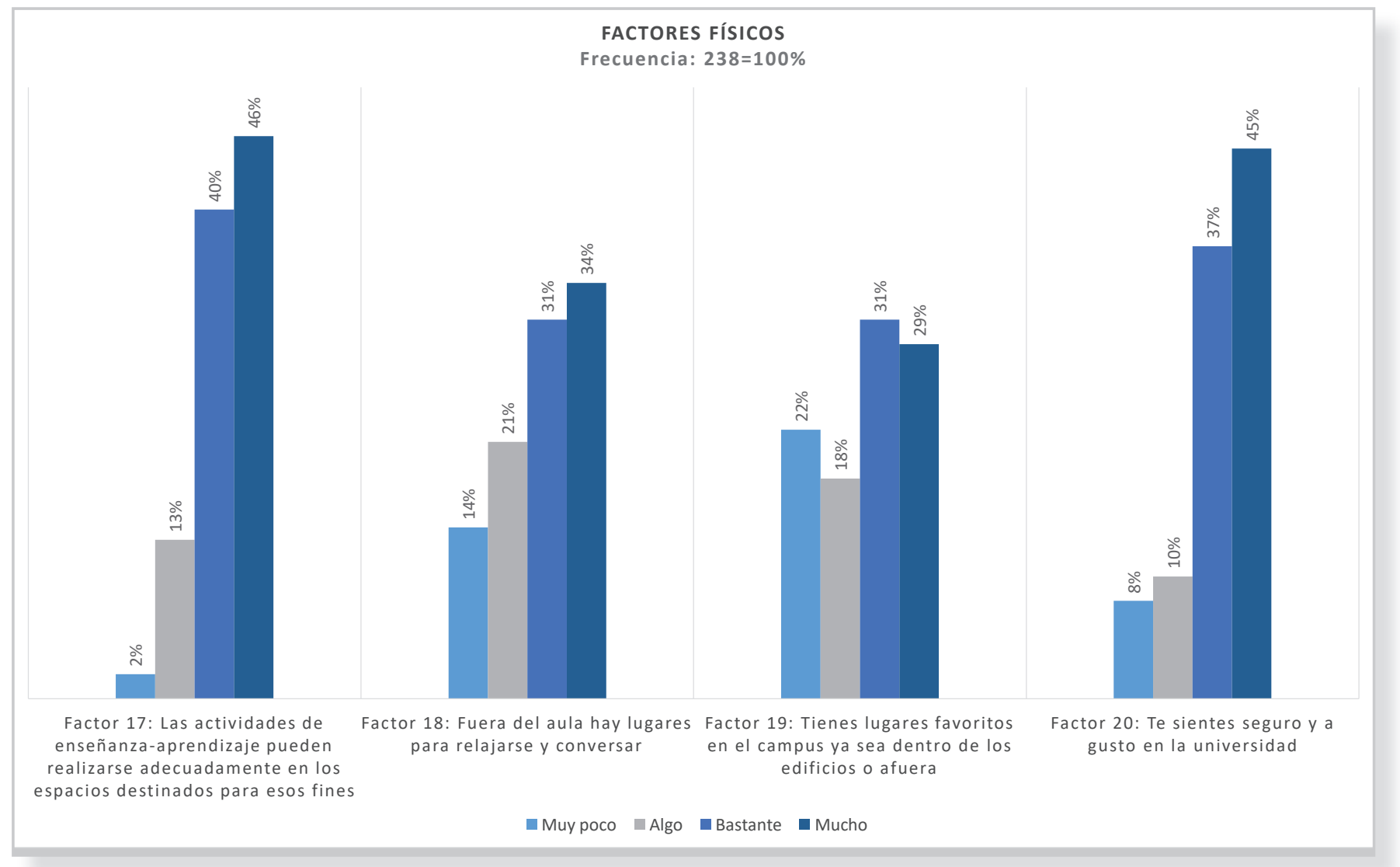

La mayoría de los estudiantes considera que la funcionalidad de la planta física (el $86 \%$ ) y sentirse seguros y a gusto en la Universidad (el $82 \%$ ) influye entre bastante y mucho en su buen desempeño académico, mientras que más del $60 \%$ considera que contar con lugares de ocio y favoritos en el campus también contribuye. Estos resultados refuerzan la condición del campus de escenario de cuidado y apoyo al desarrollo personal y académico del alumnado.

\section{Grado en que los factores contribuyen con la identificación}

En esta parte se presentan y comentan conjuntamente los resultados acerca del grado en que los factores contribuyen con la identificación con la escuela de la carrera y con la Universidad por presentar diferencias poco significativas al analizarlos por separado.

\section{Factores afectivos}

Más de la mitad de los estudiantes opina que la disponibilidad de los profesores fuera de las horas de clase y el seguimiento personalizado que le brindan contribuye con la identificación con la escuela de la carrera y con la Universidad.

Esa misma proporción considera que compartir los valores y la filosofía de la universidad facilita la identificación. Asimismo, la gran mayoría de los estudiantes (más del $70 \%$ ) considera que sentir afecto por su grupo de compañeros y por alguno de sus profesores así como considerar importante la escuela de la carrera influye entre bastante y mucho en esta identificación.

Esa misma proporción opina que la integración al grupo y el orgullo que sienten de pertenecer a la universidad contribuyen con sentirse parte de ella y de la escuela de la carrera.

Estos resultados dan cuenta de que el apoyo percibido de los profesores y la vinculación afectiva con estos y con los pares potencian el apego al contexto que soporta las relaciones. Por otra parte, la importancia atribuida a la escuela de la carrera suele producir mejores relaciones con la comunidad educativa y actitudes de protección y de orgullo hacia esta. 
Gráfico 9

Histograma Grado en que contribuyen con la identificación los factores afectivos

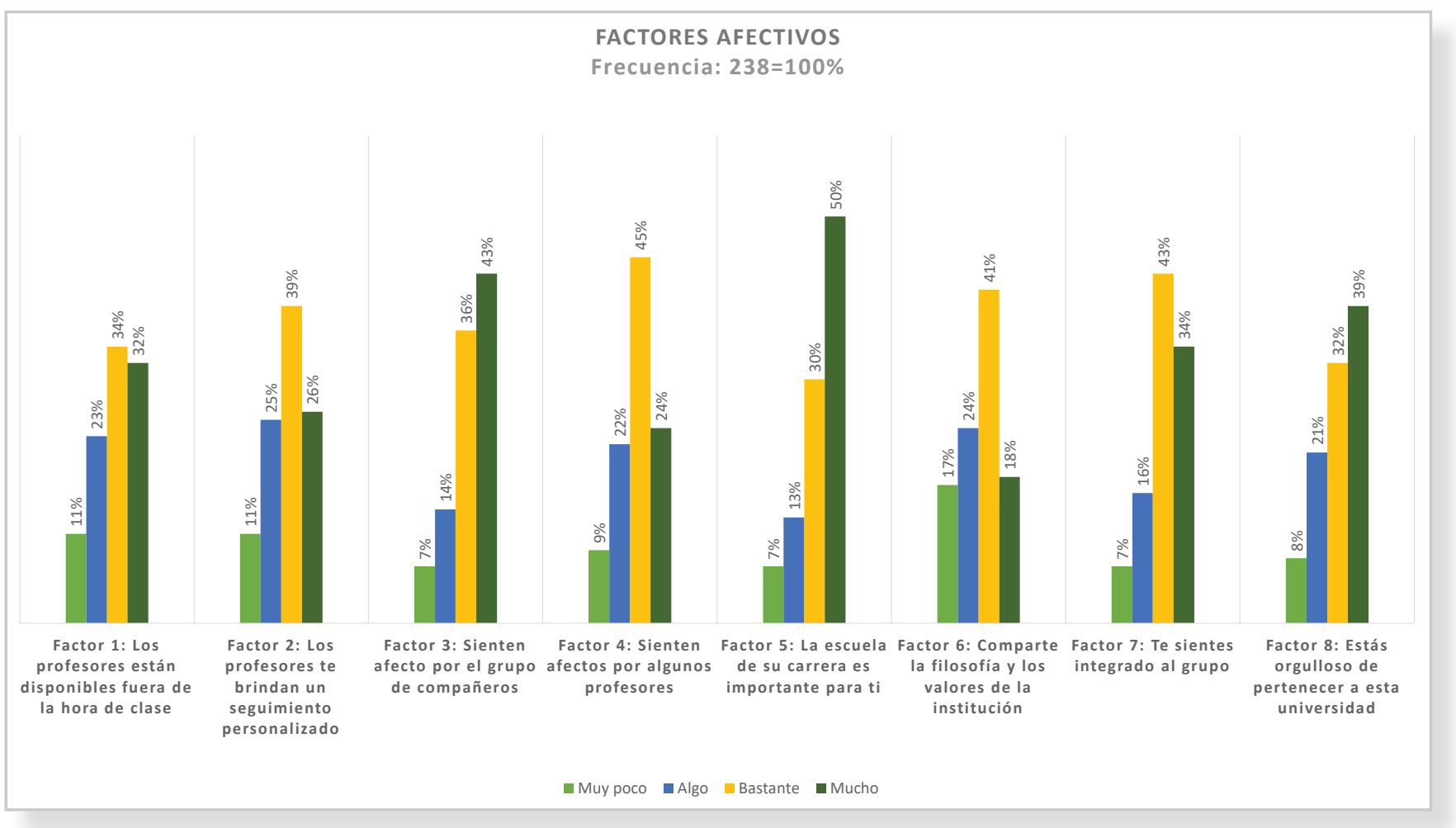

\section{Factores sociales}

Las respuestas indican que la mayoría de los estudiantes considera que hacer amigos con facilidad contribuye con la sensación de sentirse parte de la escuela de la carrera (69\%) y de la universidad (73\%). Más del $60 \%$ considera que la seguridad en sí mismo, la promoción del trabajo en equipo y el espíritu de grupo contribuyen bastante con esta sensación al igual que la promoción de la interacción social.

Estos resultados confirman los hallazgos de numerosos estudios sobre la fuerte y positiva influencia en la identificación con los centros de estudios de las interacciones sociales con profesores y pares.

\section{Gráfico 10}

Histograma Grado en que contribuyen con la identificación los factores sociales

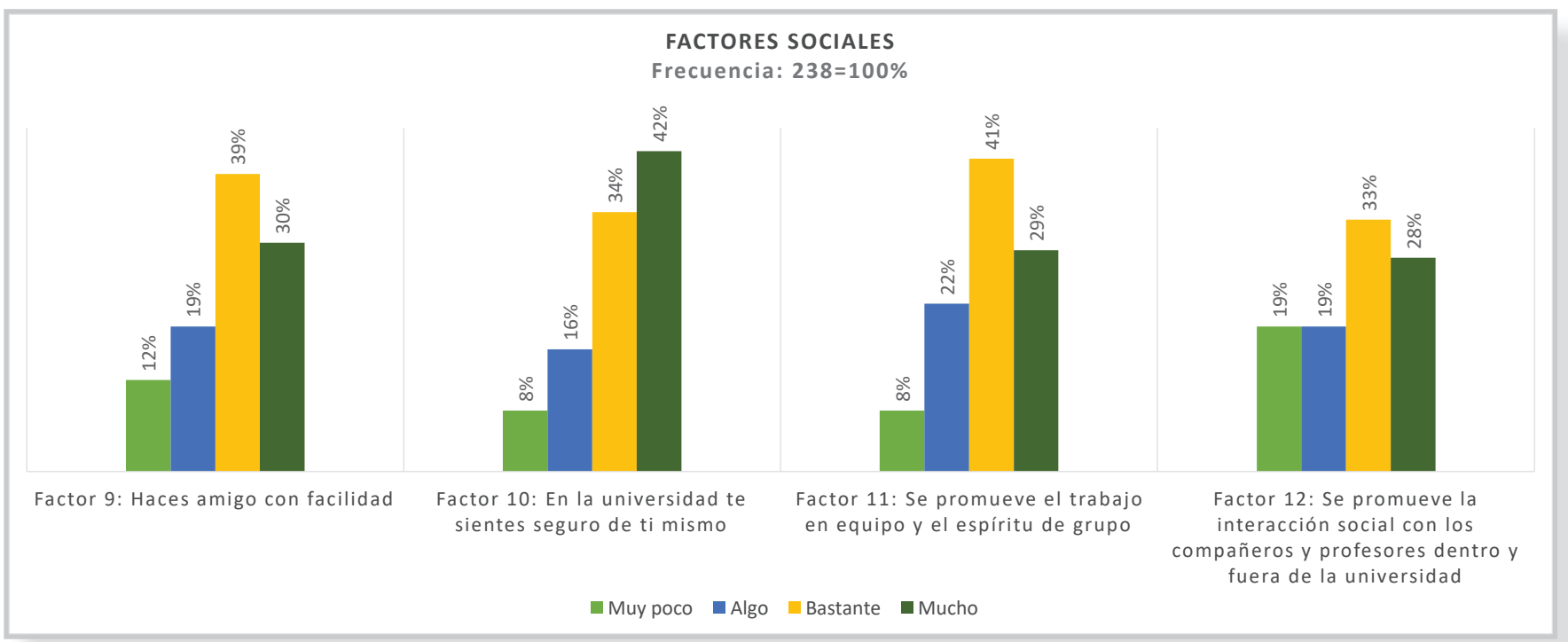

"Factores que determinan el sentido de pertenencia de los estudiantes de la PUCMM-CSTA», Leyda Brea Sención. 


\section{Factores académicos}

Más del $60 \%$ de los estudiantes considera que el dinamismo y la variedad de las actividades en el aula influye entre bastante y mucho en la identificación con la escuela de la carrera y con la Universidad. En la misma medida, la mayoría opina que los contenidos aplicables y conectados con la realidad, la planificación académica que realiza el departamento y el ambiente cordial que se respira en el aula contribuyen con esta identificación.

\section{Gráfico 11}

Histograma Grado en que contribuyen con la identificación los factores académicos

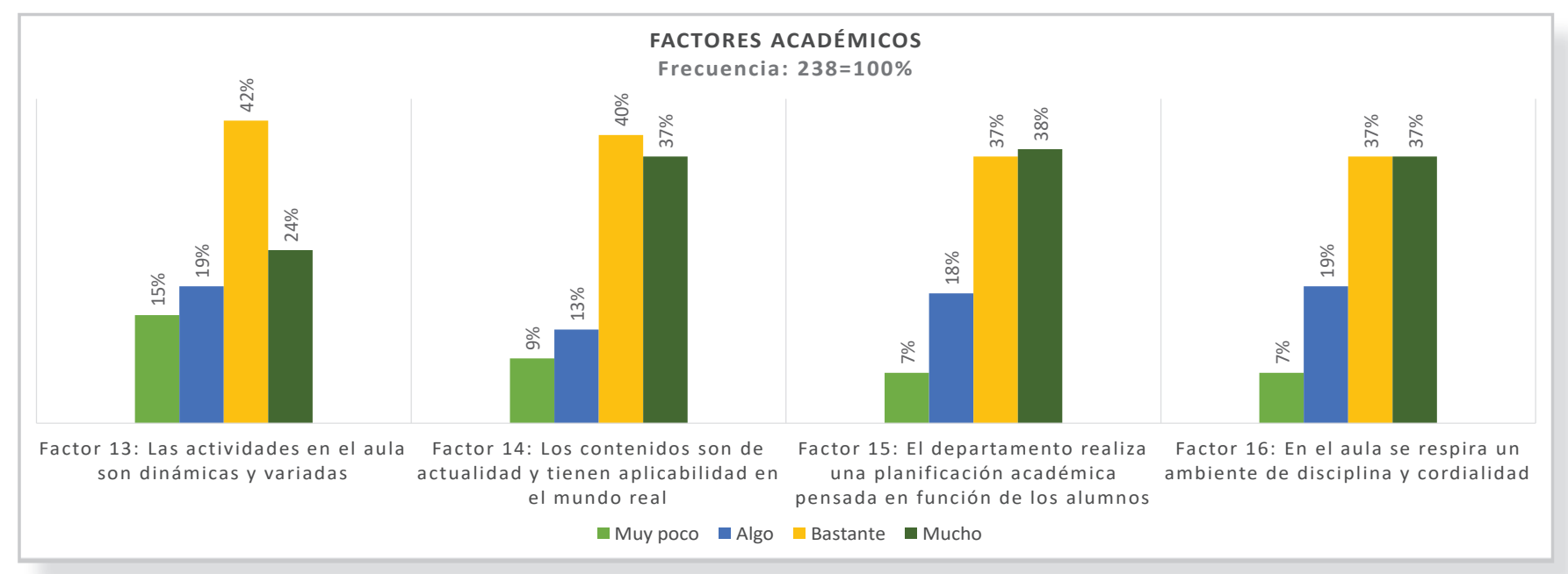

Estos resultados dan cuenta de la importancia de los factores académicos en la identificación de los estudiantes con el contexto formativo. Por un lado, la planificación es percibida como instrumento promotor de la diversidad y la inclusión lo cual contribuye con la conexión y la identificación con la escuela de la carrera y con la Universidad. Por otro, la pertinencia de los contenidos se reconoce como un signo de interés y apoyo y, junto con el buen clima de aula, se potencia esta identificación. Todo esto facilitará el desarrollo del sentido de pertenencia.

\section{Factores físicos}

Más del $70 \%$ de los estudiantes considera que la funcionalidad de la planta física influye en la identificación con la escuela de la carrera y con la Universidad. En similar medida y proporción opinan que sentirse seguros y a gusto en el campus contribuye con esta identificación. De igual manera, más del $60 \%$ piensa que contar con lugares de ocio y tener lugares favoritos en el campus contribuye con sentirse parte de la escuela de la carrera y de la Universidad.

\section{Gráfico 12}

Histograma Grado en que contribuyen con la identificación los factores físicos

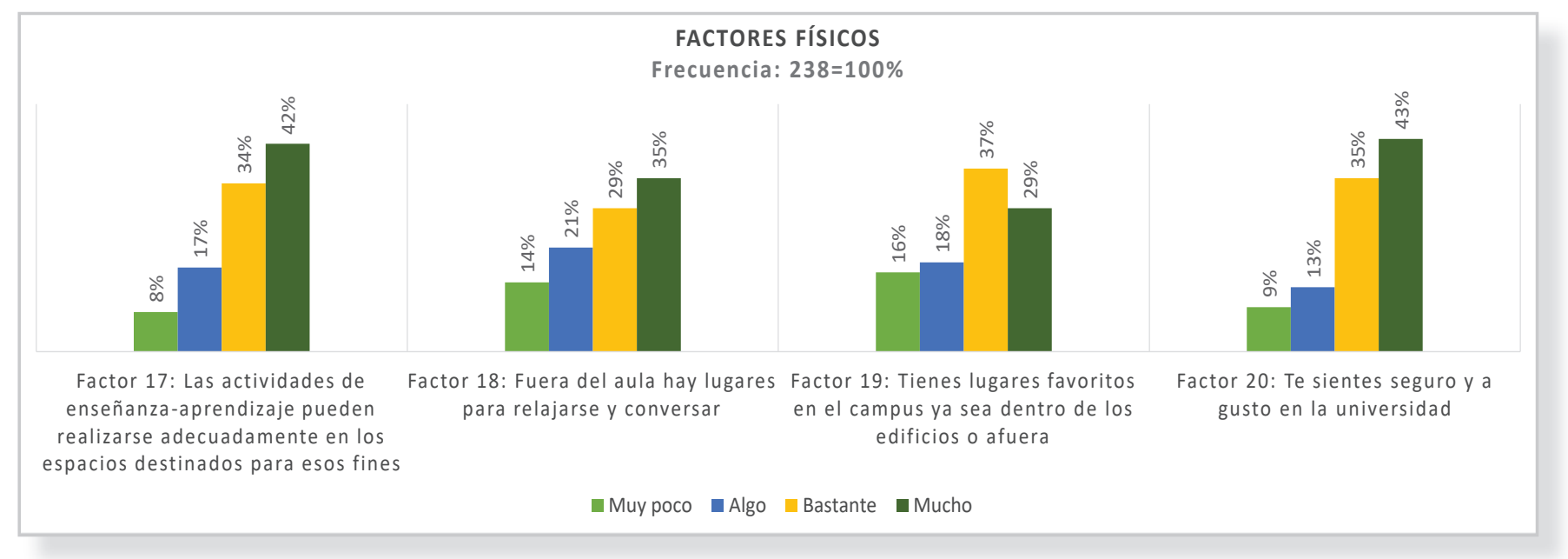


En razón de lo expuesto, se verifica la importancia de la configuración física del campus para la identificación de los estudiantes con la Universidad. En cuanto a la seguridad, al ser esta una de las necesidades básicas de las personas, a partir de su percepción se genera sensaciones de tranquilidad y bienestar que potencian las intenciones de permanecer en los lugares $\mathrm{y}$, por ende, la posibilidad de identificarse con ellos. Por otra parte, tener lugares favoritos en el campus hace referencia a la identidad de lugar, esa propiedad que incluye el distinguir en el espacio físico atributos relacionados con símbolos, con significados, con referencias sociales e históricas, con la memoria y con la pertenencia los cuales son explotables para la comunicación de los valores, la filosofía y la misión de la Institución en el mismo marco del Campus.

\section{Jerarquía de factores}

El análisis jerárquico de los factores permite identificar la fuerza en que estos determinan el sentido de pertenencia. La jerarquía es medida a partir de la media de medias obtenidas en las respuestas acerca del grado en que se experimenta el factor, la influencia de éste en el desempeño académico, en la identificación con la escuela de la carrera y con la Universidad. Mientras más alta la media mayor la jerarquía del factor. Resumiendo los resultados, se muestra que de los 80 ítems, en base a una media máxima de 4.0, los más valorados por los estudiantes son: la influencia en el buen desempeño académico de la funcionalidad de la planta física (3.38), el clima del aula (3.37), la pertinencia de los contenidos (3.28) y la planificación académica que realizan los departamentos de carrera (3.31). Sobresale también la influencia que tiene en la identificación con la escuela de la carrera la importancia que le atribuyen a esta (3.27), el sentirse seguros y a gusto en el campus (3.35) y el afecto que sienten por el grupo de compañeros (3.27).

\section{Relevancia de los factores}

La relevancia es el grado de importancia, significación o trascendencia de un factor para la construcción del sentido de pertenencia. Está definida por la valoración conjunta del grado en que se experimenta el factor, la influencia de éste en el desempeño académico, en la identificación con la escuela de la carrera y con la Universidad.

De acuerdo con los resultados, el factor afectivo más relevante es la importancia atribuida a la escuela de la carrera (5) seguido por el afecto que sienten los estudiantes por el grupo de compañeros (3). El factor social más relevante es el sentirse seguro de sí mismo en la universidad (10) seguido por la promoción del trabajo en equipo y el espíritu de grupo (11). El factor académico más relevante es la actualidad de los contenidos curriculares (14) seguido por la planificación que realiza el departamento (15).

En cuanto a los factores físicos, el más relevante es la funcionalidad de la infraestructura física (17) seguido por la seguridad y confort percibido (20).

\section{Gráfico 13}

Relevancia de los factores determinantes del sentido de pertenencia

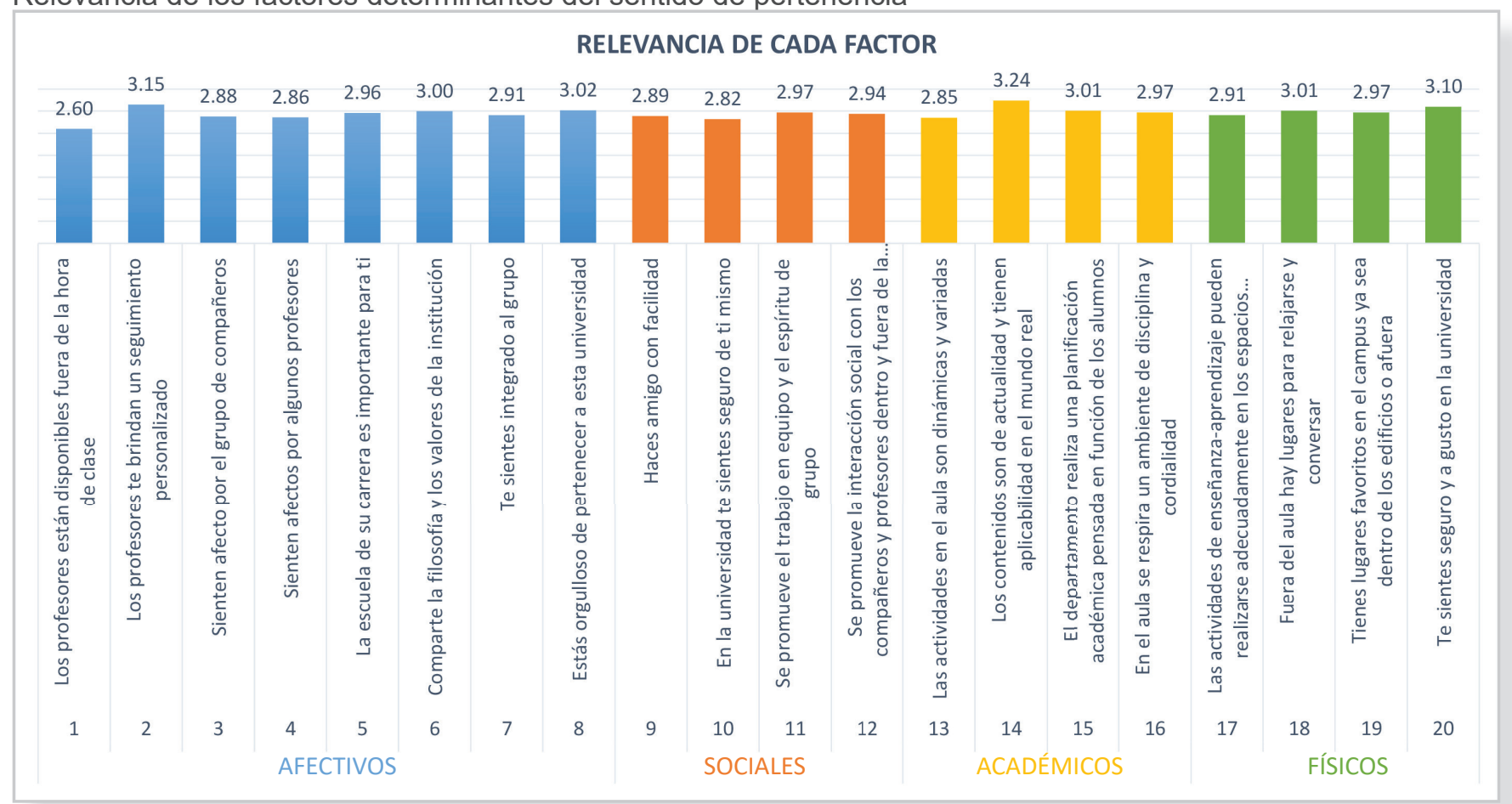

«Factores que determinan el sentido de pertenencia de los estudiantes de la PUCMM-CSTA», Leyda Brea Sención. 
En síntesis, de acuerdo con los resultados de este estudio, los factores más relevantes que determinan con más fuerza el sentido de pertenencia de los estudiantes de la PUCMM-CSTA son la pertinencia curricular (14), la importancia atribuida a la escuela de la carrera (05), el afecto hacia los compañeros (03) y la funcionalidad de la planta física.

\section{Conclusiones}

A la luz de los resultados de la investigación se concluye lo siguiente:

El sentido de pertenencia no solo se nutre de los vínculos afectivos, sino también de la riqueza curricular que da sentido a toda la experiencia formativa. Los lazos afectivos posibilitan la identificación con la escuela de la carrera y con la Universidad a causa del apego emocional que se deriva de la amistad, mientras que un currículo pertinente ayuda a que los alumnos consideren importante la escuela y la Universidad y a generar en ellos motivación y participación, lo que contribuye a su vez con la persistencia y el logro. Esto, junto con un clima de aula favorable al aprendizaje, influirá en que los alumnos se sientan parte del contexto académico y de la Institución, marco promotor de oportunidades de desarrollo académico, social y humano.

Cuando los alumnos perciben que los profesores, el departamento y la universidad se interesan en ellos suelen comprometerse con los estudios. La labor del profesorado trasciende los límites del aula; por tanto, un cuerpo docente competente, actualizado y dedicado a los estudiantes podría coadyuvar a desarrollar en ellos compromiso y buena actitud hacia el aprendizaje, influir en su implicación académica y en los procesos de vinculación institucional.

Por otra parte, aunque los estudiantes no visualizan la relación de la filosofía institucional con su desempeño académico, la conocen y comparten sus valores. Se destaca que las oportunidades de interactuar socialmente con docentes y pares suelen favorecer la integración grupal de los alumnos y el surgimiento de lazos afectivos por su trasfondo didáctico, social y recreativo, por tanto la promoción de estas interacciones puede potenciar el deseo de persistir en sus estudios, el buen desempeño académico y la identificación con la carrera y con la Universidad. Asimismo, la infraestructura física puede influir en estaidentificación ya que sus características modelan los escenarios donde ocurren la mayoría de las interacciones sociales y académicas.

Un ambiente físico funcional, confortable, seguro y diferenciado, conlleva generalmente al disfrute de la estancia en el campus y a la construcción de significados y recuerdos que perdurarán por muchos años en la memoria de todos.

\section{Recomendaciones}

Las conclusiones han motivado la reflexión sobre aspectos de las universidades relacionados con las dimensiones del sentido de pertenencia. Derivadas de esta reflexión se realizan las siguientes recomendaciones:

a) Sobre el cuidado y el apoyo:

- Facilitar la adecuada atención al estudiantado mediante el aumento de la cantidad de profesores con contratos fijos, que estén dotados de espacio y equipos necesarios para interactuar con los estudiantes y cuenten con un perfil caracterizado por buenas relaciones humanas, competencia disciplinar y pedagógica.

- Comunicar a los alumnos elevadas expectativas de desempeño y mantenerlas.

- Proveer oportunidades de nivelación para estudiantes de bajo rendimiento.

b) Sobre la identificación con la institución:

- Difundir y promover los valores y la filosofía de la institución de manera estratégica, directa y vivencial en el Campus, por medio de charlas sistematizadas, actividades artísticas, lecturas breves impresas y digitales.

- Exponer la pertinencia curricular y la aplicabilidad de los contenidos relacionados con la filosofía de la institución, a través de una mayor participación en proyectos de extensión y difusión de buenas prácticas.

- Fortalecer la idea del Campus como marca mediante la dotación de elementos de identidad más físicos que simbólicos que lo distingan 
en la trama urbana como un espacio único diferenciado (elementos arquitectónicos, pavimentos, colores, texturas).

c) Sobre la interacción social:

- Proveer oportunidades y escenarios para la interacción social y académica de los estudiantes con compañeros y profesores, en actividades extracurriculares como exposiciones, coloquios, viajes académicos, intercambios interuniversitarios, eventos sociales y entornos digitales colaborativos.

- Promover y fortalecer los grupos de trabajo y comités de estudiantes, mediante apoyo logístico y económico y la participación en proyectos concretos de interacción académica, social y comunitaria.

d) Sobre la habitabilidad del Campus:

- Adecuar la planta física del Campus considerando los recorridos peatonales y la permanencia en las áreas abiertas. Dotarla de condiciones para el encuentro y la interacción de los miembros de la comunidad académica; disponer de más zonas peatonales; proveer señalización adecuada y suficiente; dotar de lugares amplios, flexibles, pasibles de personalizar.

- Facilitar la movilidad en los edificios y el Campus y la accesibilidad en los mismos.

- Mejorar las condiciones ambientales de las áreas de aprendizaje mediante la facilitación de ventilación e iluminación natural.

e) Sobre la gestión académica:

- Fomentar la actualización periódica de contenidos curriculares mediante la investigación, la atención a los avances tecnológicos, tendencias socioculturales y económicas, el estudio de buenas prácticas, el flujo de información interinstitucional, el contacto con egresados y el medio laboral.

- Promover altas expectativas y estándares académicos para las escuelas, los docentes y el estudiantado en cuanto a calidad, innovación, rigor científico, valores humanos y éticos.
- Dotar a los departamentos de carrera de recursos humanos para apoyar al estudiantado: coordinadores, tutores, administradores de recursos físicos y digitales, asistentes para la investigación y la promoción. Por tanto, un director $y$ un asistente administrativo no son suficientes.

- Promover la visión de los departamentos académicos como una micro-universidad dentro de la Universidad.

El sentido de pertenencia como proyecto estratégico para el fortalecimiento y la mejora institucional podría conducir a las universidades a múltiples resultados positivos como competitividad, retención estudiantil y orgullo de pertenencia.

Este, como todo proyecto, implica el planteamiento de objetivos alcanzables y una planificación de recursos en base a los resultados esperados de calidad y sostenibilidad. Asumir este proyecto conlleva reconocer que el sentido de pertenencia es un componente esencial y transversal del desarrollo académico, social y humano de los alumnos. Uno de los objetivos de esta investigación fue contribuir con este reconocimiento.

\section{Referencias}

Anderman, L. (18 de 4 de 2011). School belonging. Recuperado el 2 de 3 de 2013, de education.com: http://www.education.com/reference/article/schoolbelonging/

Astin, A. (January de 1968). The college environment. Washington, D.C.: American Council on Education.

Boyer, E. (1990). Campus Life. In search of Community. Carnegie Foundation for the Advancement of Teaching. Princeton, New Yersey: Princeton University Press.

Brea, L. (2009). El sentido de pertenencia en los estudiantes de arquitectura del Recinto Santo Tomás de Aquino de la Pontificia Universidad Católica Madre y Maestra. Diagnóstico. Murcia, España: Universidad de Murcia.

Brea, L. (2015). Factores determinantes del sentido de pertenencia en los estudiantes de Arquitectura del Campus Santo Tomás de Aquino de la Pontificia Universidad Católica Madre y Maestra. Murcia, España: Universidad de Murcia. 
Corraliza, J. A. (1987). La experiencia del ambiente. Madrid: Editorial Tecno.

Fenster, T. (2005). Gender and the City:The Different Formations of Belonging. En L. N. Seager, A Companion to Feminist Geography Routledge (págs. 242-256). Malden, Massachuset, USA: Blacwell Publishing Ltd. Recuperado 2012, https:// iwww.tau.ac.il/ tobiws/gender_companion.pdf

Freeman, T., Anderman, L., \& Jensen, J. (2007). Sense of belonging in college freshmen at the classroom and campus levels. The Journal of Experimental Education, 75(3), 203-220.-

González, M. T. (2010). El alumno ante la escuela y su propio aprendizaje: Algunas líneas de investigación en torno al concepto de implicación. Revista Iberoamericana sobre calidad, eficacia y cambio en educación, 8(4), 10-30.

Hargreaves, D. (1986). Las relaciones interpersonales en la educación (3 ed.). Madrid: Narcea .

Kenney, D. R., Dumont, R., \& Kenney, G. (2005). Mission and Place: Strengthening Learning and Community through Campus Design. (A. C. Education., Ed.) Westport, CT: Rowman \& Littlefield Publishers .

Leff, H. L. (1978). Experience, environment and human potencials. New York: Oxford University Press.

Lehmann, C. (1994). El sentido de pertenencia como catalizador de una educación de calidad. (CEP, Ed.) Estudios Públicos, 56, 141-162.

Maslow, A. (1954). Motivación y Personalidad (3 ed.). Madrid, España: Ediciones Díaz de Santos.

Muñoz, J. M. (2005). El lenguaje de los espacios: interpretación en términos de educación. Teoría educativa (17), 209-226.

Osterman, K. (2000). Students'need for belonging in the school community. (A. E. Association, Ed.) Review of Educational Research, 70(3), 323-367. Recuperado el 14 de octubre de 2012, de http:// www.jstor.org/stable/1170786

Pérez, Z. P. (Noviembre de 2010). Las dinámicas interactivas en el ámbito universitario: el clima de aula. Revista Electrónica Educare, 14(Extraordinario), 7-20.
Proshansky, H. M., Fabian, A. K., \& Kaminoff, R. (Mar de 1983). Place-identity: Physical world socialization of the self. Journal of Environmental Psychology, $3(1), 57-83$.

Salvador, A. C. (2010). Prácticas de investigación que escuchan la voz del alumnado: mejorar la universidad indagando la experiencia. Revista de curriculum y formación del profesorado, 14(3), 7588. Recuperado el 30 de abril de 2013, de http:// www.ugr.es/ recfpro/rev143ART5.pdff

Soria, M. S., Martínez, I. M., Esteve, E. B., Gumbau, S. L., \& Gumbau, R. G. (JUNIO de 2005). Bienestar psicológico en estudiantes universitarios: facilitadores y obstaculizadores del desempeño académico. (S. d. Murcia, Ed.) Anales de Psicología, 21(1), 170-180.

Stokols, D. (1977). Perspectives on environment and behavior. New York: Plenum Press.

Strayhorn, T. (2012). College Students' Sense of Belonging. New York: Routledge.

Thomas, L. (2012). Bulding student engagement and belonging in higher education at a time of change: final report from the What Works? Student Retention \& Success programme. The Higher Education Academy. London: Paul Hamlyn Foundation.

Thompson, H. (2007). The Need to Belong and Student Grades: Is There a Correlation? Recuperado el 20 de marzo de 2013, de Counselor Education Master's Theses. Paper 105.: http://www.digitalcomons.edu/ edc_theses/105

Vargas, G. M. (2007). Factores asociados al rendimiento académico en estudiantes universitarios, una reflexión desde la calidad de la educaclón superior pública. Revista Educación, 31(1), 43-63.

Vidal, T., \& Pol, E. (2005). La apropiación del espacio. Una propuesta teórica para comprender la vinculación entre las personas y los lugares. (F. d. Psicología, Ed.) Anuario de Psicología, 36(3), 281-297.

Willms, J. D. (2003). Student Engagement at School. A sense of belonging and participation. Results of PISA 2000. OECD, USD 24, GBP 14, JPY 2700, MXN 245. 


\section{Anexo 1: Cuestionario aplicado}

Valora los 20 aspectos de la lista relacionados con tu vida académica, la escuela de tu carrera y la Universidad Responde a las preguntas marcando con una X la opción que mejor recoja tu valoración de acuerdo a la escala que se presenta.

ESCALA

\begin{tabular}{|c|c|c|c|}
\hline $\begin{array}{l}\text { Muy poco } \\
1\end{array}$ & $\begin{array}{l}\text { Algo } \\
2\end{array}$ & $\begin{array}{l}\text { Bastante } \\
3\end{array}$ & $\begin{array}{l}\text { Mucho } \\
4\end{array}$ \\
\hline
\end{tabular}

FACTORES AFECTIVOS

1. Los profesores están disponibles fuera de las horas de clase.

2. Los profesores te brindan un seguimiento personalizado.

3. Sientes afecto por el grupo de compañeros.

4. Sientes afecto por algunos profesores.

5. La escuela de tu carrera es importante para ti.

6. Compartes la filosofía y los valores de la institución.

7. Te sientes integrado al grupo.

8. Estás orgulloso de pertenecer a esta Universidad.

\section{FACTORES SOCIALES}

9. Haces amigos con facilidad.

10. En la Universidad, te sientes seguro de ti mismo.

11. Se promueve el trabajo en equipo y el espíritu de grupo.

12. Se promueve la interacción social con compañeros y profesores dentro y fuera de la Universidad, en actividades extracurriculares como viajes académicos o eventos.

\section{FACTORES ACADÉMICOS}

13. Las actividades en el aula son dinámicas y variadas.

14. Los contenidos son de actualidad y tienen aplicabilidad en el mundo real.

15. El departamento realiza una planificación académica (bloques, horarios, oferta) pensada en función de los alumnos.

16. En el aula se respira un ambiente de disciplina y cordialidad.

\section{FACTORES FÍSICOS}

17. Las actividades de enseñanza-aprendizaje pueden realizarse adecuadamente en los espacios destinados para esos fines (aulas, talleres, laboratorios).

18. Fuera del aula hay lugares para relajarse y conversar.

19. Tienes lugares favoritos en el campus, ya sea dentro de los edificios o afuera.

20. Te sientes seguro y a gusto en la Universidad. Gracias por tu colaboración!

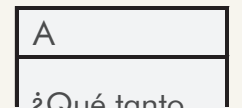

¿Qué tanto experimentas

esto en la

Universidad?

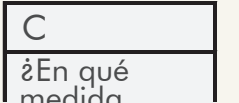

medida

contribuye a

que te sientas

parte de la

escuela de tu

carrera?

\begin{tabular}{|l|}
\hline $\mathrm{D}$ \\
\hline żEn qué \\
medida \\
contribuye a \\
que te sientas \\
parte de la \\
Universidad?
\end{tabular}
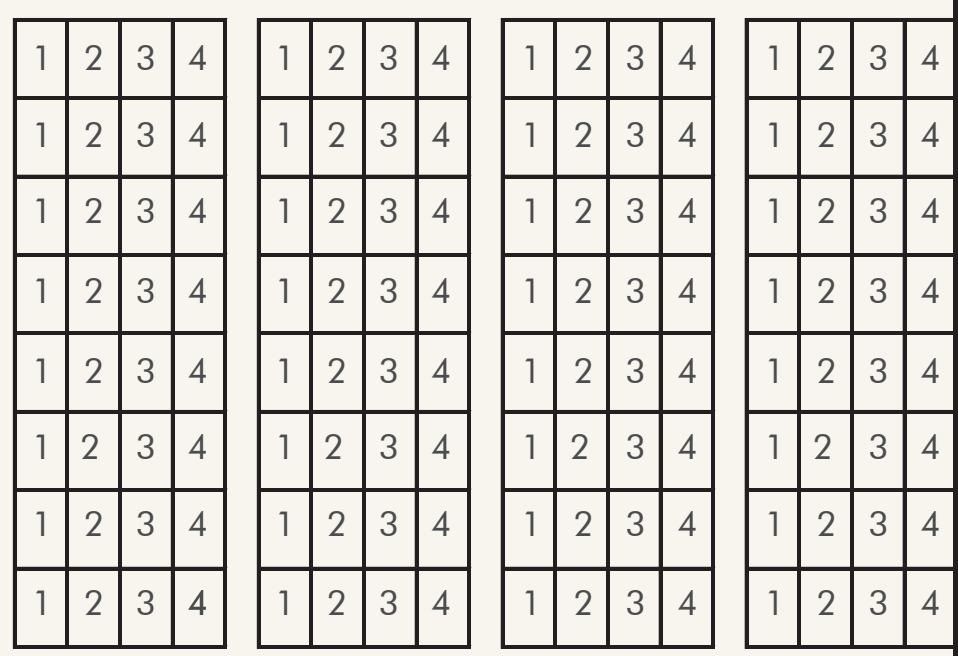

\begin{tabular}{|l|l|l|l|}
\hline 1 & 2 & 3 & 4 \\
\hline 1 & 2 & 3 & 4 \\
\hline 1 & 2 & 3 & 4 \\
\hline 1 & 2 & 3 & 4 \\
\hline 1 & 2 & 3 & 4 \\
\hline 1 & 2 & 3 & 4 \\
\hline 1 & 2 & 3 & 4 \\
\hline 1 & 2 & 3 & 4 \\
\hline
\end{tabular}

\begin{tabular}{|l|l|l|l|}
\hline 1 & 2 & 3 & 4 \\
\hline 1 & 2 & 3 & 4 \\
\hline 1 & 2 & 3 & 4 \\
\hline 1 & 2 & 3 & 4 \\
\hline 1 & 2 & 3 & 4 \\
\hline 1 & 2 & 3 & 4 \\
\hline 1 & 2 & 3 & 4 \\
\hline 1 & 2 & 3 & 4 \\
\hline
\end{tabular}

\begin{tabular}{|l|l|l|l|}
\hline 1 & 2 & 3 & 4 \\
\hline 1 & 2 & 3 & 4 \\
\hline 1 & 2 & 3 & 4 \\
\hline 1 & 2 & 3 & 4 \\
\hline
\end{tabular}

\begin{tabular}{|l|l|l|l|}
\hline 1 & 2 & 3 & 4 \\
\hline 1 & 2 & 3 & 4 \\
\hline 1 & 2 & 3 & 4 \\
\hline 1 & 2 & 3 & 4 \\
\hline
\end{tabular}
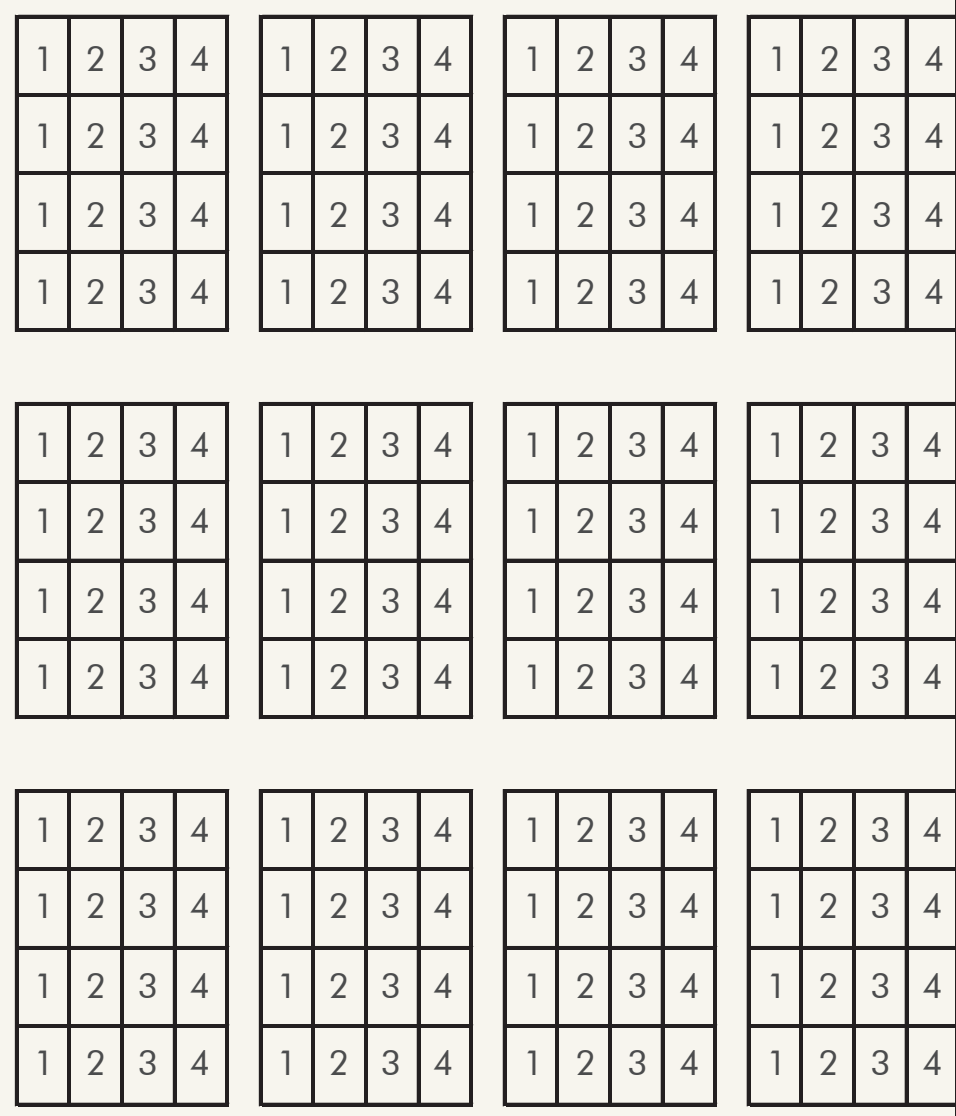
Anexo 2: Esquema utilizado para el análisis de los datos
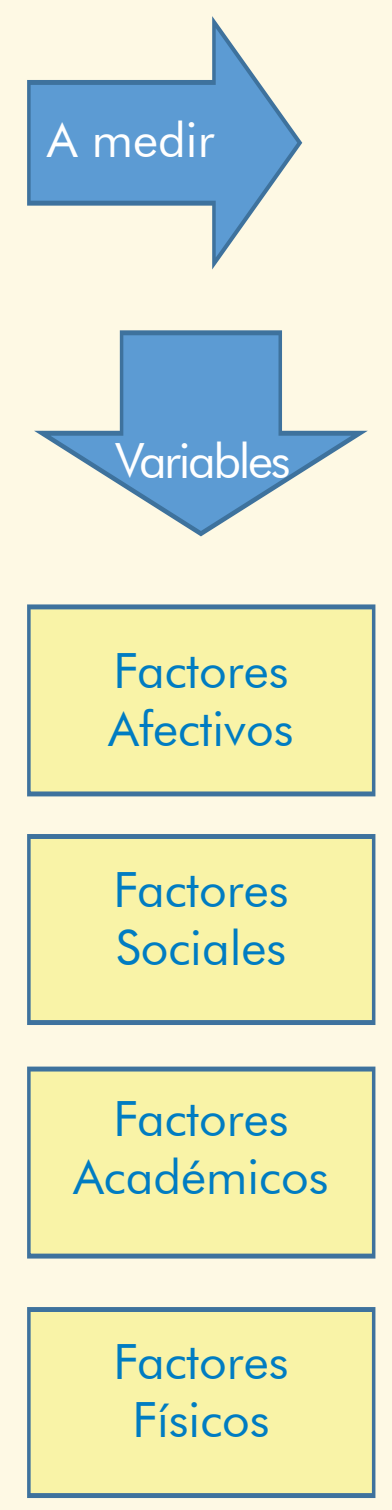
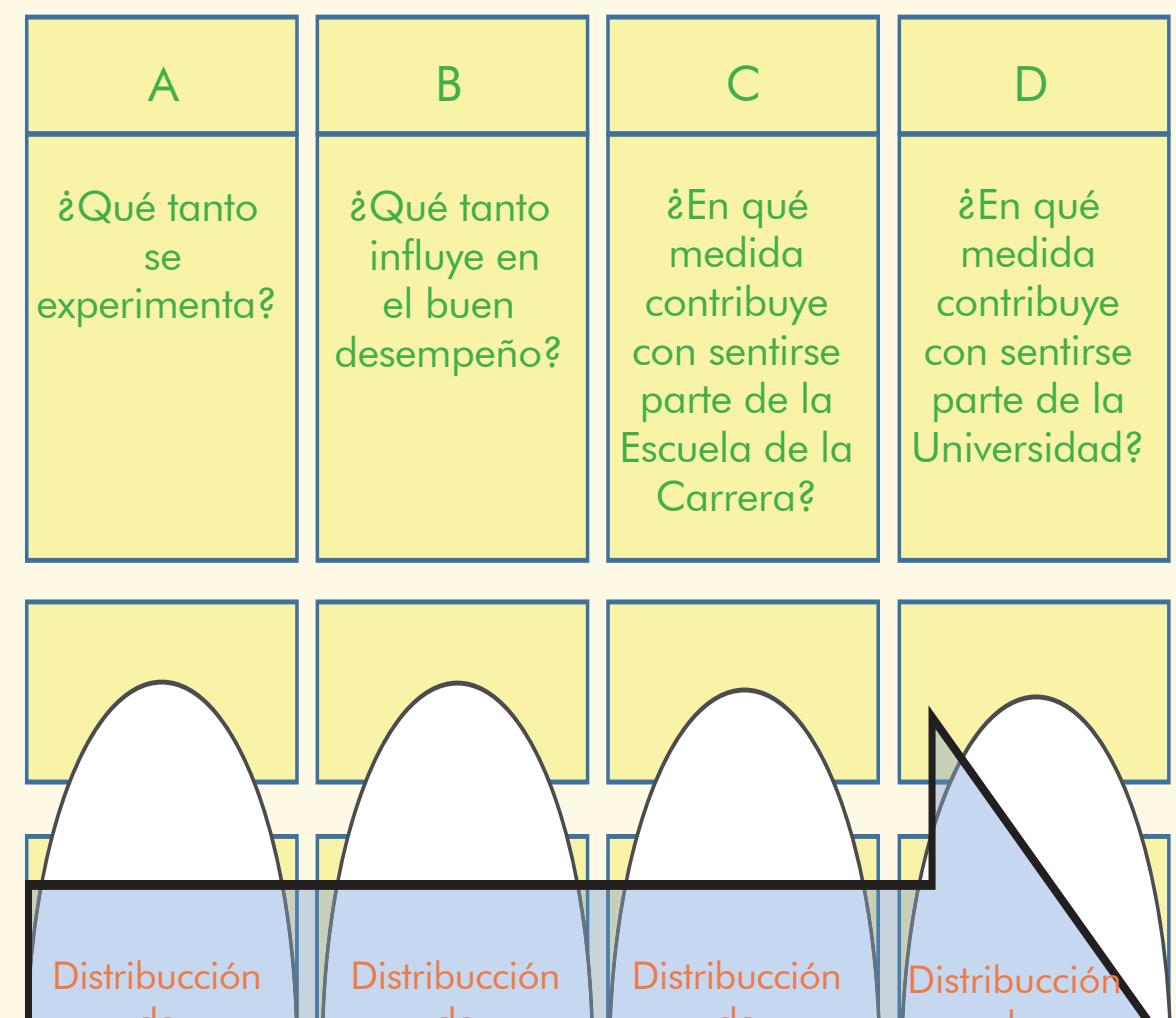

de

frecuencia

Media

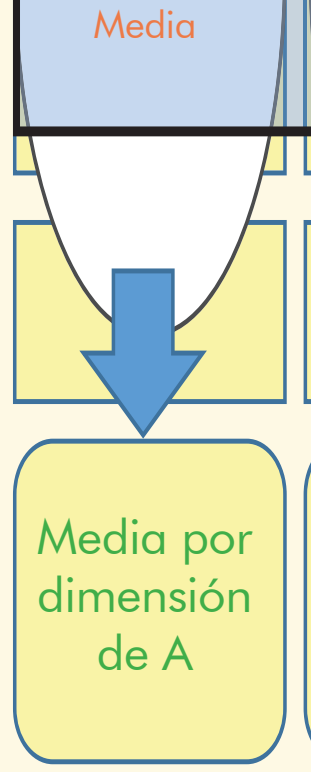

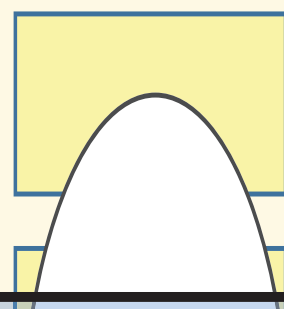

Distribucción

$$
\text { de }
$$

frecuencia Media

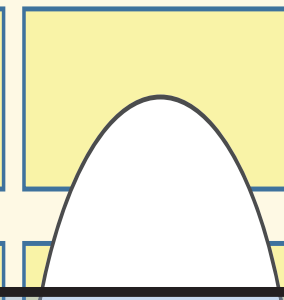

Distribucción

de

frecuencia

Media
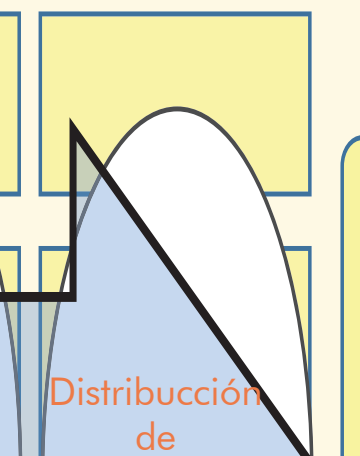

$\frac{0}{u}$
$\frac{c}{0}$
$\frac{d}{0}$
$\frac{1}{\alpha}$ 